\section{Violence in childhood-onset schizophrenia}

\author{
Randal G. Ross, 1 Julia Maximon,1 \\ Jonathan Kusumi,1,2 Susan Lurie ${ }^{1}$ \\ 1Department of Psychiatry, University \\ of Colorado Denver, Aurora, CO; \\ 2Department of Psychiatry, Denver \\ Health and Hospitals, Denver, CO, USA
}

\section{Abstract}

Violence is elevated in older adolescents and adults with schizophrenia; however, little is known about younger children. This report focuses on rates of violence in younger children with schizophrenic-spectrum illnesses. A retrospective review of structured diagnostic interviews from a case series of 81 children, ages 4-15 years of age, with childhood onset of schizophrenic-spectrum illness is reported. Seventy-two percent of children had a history of violent behavior, including 25 children (31\%) with a history of severe violence. Of those with a history of violence, $60 \%$ had a least one episode of violence that did not appear to be in response to an external stimulus (internally driven violence). There was no significant impact of age or gender. For many children, these internally driven violent episodes were rare and unpredictable, but severe. Similar to what is found in adolescents and adults, violence is common in children with schizophrenic-spectrum ilnesses. General violence prevention strategies combined with early identification and treatment of childhood psychotic illnesses may decrease the morbidity associated with childhood psychotic violence.

\section{Introduction}

Every few years, there is a well-publicized case describing unpredictable violence in an individual with significant psychotic symptoms. These cases generate a strong interest in both the scientific and lay communities about the relationship between violence and schizophrenia and schizophrenia-like illnesses (schizophrenia, schizoaffective, and delusional disorder). The majority of these wellpublicized cases and the associated scientific literature are in older adolescents and young adults; however schizophrenia-spectrum illnesses can begin much earlier in childhood and little is known whether schizophrenia in young children is associated with violence.

A majority of adolescents and adults with schizophrenia-spectrum illnesses are not violent. In addition, individuals with schizophrenia-spectrum illnesses constitute only a small part of the population and are therefore responsible for only a minority of violent acts. However, adults and adolescents with schizophrenia-spectrum illnesses are 4-8 times more likely to perpetrate a violent act than general population groups with a birth cohort study finding that,1-4 over a 1-year period, $15 \%$ of young adults with schizophrenia were convicted of a violent crime. ${ }^{5}$ Studies of convicted homicide perpetrators suggest that chronic psychosis may account for $6-15 \%$ of homicides, ${ }^{6,7}$ The impact of schizophrenia-spectrum illness on violence risk is similar to, but appears to be separate from, that found for the impact of substance use disorders on violence risk. The excessive perception of threat associated with schizophrenia contributes to risk for violence above and beyond the acute substance use and history of conduct disorder contributions found with substance use disorders. The unique impact of psychosis suggests that schizophrenia-related violence may require different intervention strategies and deserves independent study. ${ }^{5}$

While the relationship between psychosis and violence is well demonstrated in older adolescents and adults, very little known about the rates of violence in children and younger adolescents with chronic psychotic illness. Conner et al. ${ }^{8}$ reported while $68 \%$ of a clinical sample had a history of aggression, in a multiple regression analysis psychosis had no impact on violence rates. However, the sample was predominantly from a residential treatment facility, where psychosis was infrequent and a pattern of aggression may have been a factor in the decision to utilize that type of facility. Khalid et al. ${ }^{9}$ reviewed clinic intake checklists on 212 children, ages 7-18 years, with psychosis. The sample included children with transient psychosis and those with more mild symptoms (e.g. diagnosis of schizotypal personality disorder). Thirty-nine (18\%) of the children were noted to have a history of aggression, with aggression defined as fighting, bullying, aggression or [...] violent assault (stabbing or use of other weapon, severe physical attack). There were very few differences between psychotic children with and without aggression, with positive findings limited to psychotic children with aggression having more irritability, more overt relationship difficulties, and more non-aggressive conduct problems. Substance misuse was rare and did not differentiate aggressive from non-aggressive psychotic youth. This report provided an initial estimate of aggression, but had two notable limitations. First, because of its inclusion of subjects with transient or mild symptoms (e.g. schizotypal personality disorder), the generalizability to a more severe chronical-
Correspondence: Randy Ross, University of Colorado Denver, P0 Box 6508, Mailstop F546, Aurora, C0, 80045, USA.

E-mail: randy.ross@ucdenver.edu

Key words: childhood-onset schizophrenia, violence, case series.

Acknowledgements: the authors wish to thank all the participating children, their families, and the clinicians with whom we have worked. We acknowledge Kate Hanna, Anna Riddoch, Shari Heinlein, and Nina Compagnon for their help on this project. Dr Julia Maximon in currently in private practice in Boulder, CO, USA.

Funding: this study was supported by the National Institute of Mental Health (MH056539, MH066115, MH068582, and MH086383). This institution played no additional role in study design or manuscript preparation.

Received for publication: 25 September 2011. Revision received: 21 September 2012. Accepted for publication: 6 November 2012.

This work is licensed under a Creative Commons Attribution NonCommercial 3.0 License (CC BYNC 3.0).

(C) Copyright R.G. Ross et al., 2013

Licensee PAGEPress, Italy

Mental Illness 2013; 5:e2

doi:10.4081/mi.2013.e2

ly affected group may be limited. Second, because of a methodological focus on checklists, more detailed exploration of the type and causes of aggression were not feasible.

This report is, to our knowledge, the first attempt to review the frequency and form of violence in children with a fully expressed psychotic illness (schizophrenia, schizoaffective, or related disorder).

\section{Materials and Methods}

\section{Subjects}

Information was available from eighty-one of eighty-two sequentially identified children with schizophrenia or related illnesses recruited as part of an ongoing study of childhood schizophrenia. All children were referred to the program by community providers already concerned about the possibility of psychotic illness. No formal assessment of neighborhood-of-origin or socioeconomic status was completed; however, referral sources ranged from private practitioners to local mental health centers, and included urban, suburban, and rural areas. Socioeconomic status was equally broad. As part of the ongoing study, these children were diagnosed using 
DSM-IV criteria, ${ }^{10}$ using a best estimate diagnostic approach after a structured diagnostic interview completed by experienced clinicians (MD, D0, MSW). 11 We have reported on the process by which we identify psychosis in school-age and preschool children; ${ }^{12,13}$ diagnostic criteria for childhood-onset schizophrenia are identical to those used for older adolescent and adult populations. Violence is not part of the diagnostic criteria. As the goal was to explore violence in children with fully expressed psychotic illnesses, children who had sub-diagnostic symptoms (at-risk children) ${ }^{14}$ were not included. Children up to 15 years of age were included; however, all children had onset of psychotic symptoms prior to their $13^{\text {th }}$ birthday. The children had a mean age of $10 \pm 3$ years (range 4-15 years of age). Since a history of conduct disorder or physical or sexual abuse may be associated with both psychosis and violence, all assessments included an assessment in these areas as part of the structured interview. For child abuse and neglect, both the parent/guardian interview and the interview of the child asked directly about a history of abuse and neglect. In addition, the parent/guardian interview included questions about legal or social service involvement which, when positive, was followed up with questions about the reasons behind such involvement. Eight (9.8\%) of the children had been the victim of child abuse; in most cases the abuse was a single or time-limited experience. No child had been the victim of severe neglect. Additional demographic information is available in Table 1.

\section{Assessment}

As part of the evaluative process, a summary of clinical information is prepared for each child. A history of violence was not a specific probe for the evaluations; however was noted when present. These summaries were reviewed by psychiatrists (JM or JK); 56 (69\%) were reviewed by both physicians. The summaries were reviewed for any presence of violence occurring at any time up to the assessment interview. Violence was defined as any act of physical aggression towards self, others, animals or objects. This definition is similar to definitions proposed by others. 15,16 To match adolescent and adult studies of violence, only violent acts were considered; violent thoughts such as violent ideation and command auditory hallucinations that were not acted upon are often not included in violence definitions and were excluded from the definition. Verbal aggression was not well-documented in the clinical write-ups and thus also excluded from the violence definition. If a history of violence was identified, the history was further characterized as to whether there was a history of least one act of severe violence and whether the history contained at least one episode of internally driven violence. Severe violence was defined as any act which either caused significant injury to a human or an animal or would have caused such injury if no intervention had occurred. Internally driven violence was defined as a physical act of aggression that would be experienced as illogical or out of context by an observer. That is, violence that is unrelated to external environment, with no logical endpoint, not enacted to resolve conflict or relieve stress such as self-harming behavior. Internally driven violence includes physical aggression which exceeds a level of typical force or boundary, or violence with no apparent intent or that is not logically matched to its intent. This definition is similar to the definitions for medical or psychotically-driven violence utilized by others. ${ }^{17}$ The youngest age at which an internally driven violent act occurred was noted where possible.

\section{Inter-rater reliability}

Inter-rater reliability as to the presence or absence of violence and, if violence was present, as to whether the violence was internally driven, was assessed based on agreement between two reviewers (J.M. and J.K.); disagreements were decided based on the input of a senior child psychiatrist (R.G.R.).

\section{Results}

The two reviewers agreed on the presence or absence of violence in $93 \%$ of cases. When violence was present, the two reviewers agreed on the presence or absence of internally driven violence in $89 \%$ of cases. Table 2 lists examples of internally driven violence.

Table 1 summarizes the rates of violence both by types of violence (any violence, severe violence, internally-driven violence) and by victim of that violence (self, others, animals). Internally driven violence was identified in thirty-five children ( $43 \%$ of the entire sample); this includes all 25 children with a history of severe violence.

Table 3 summaries the impact of demographic and comorbid factors on violence rates. Comorbid conduct disorder was associated with increased rates of severe violence, internally-driven violence, and violence towards animals, while a history of being the victim of abuse was associated with an increased rate of violence towards self. However, these comorbidities were relatively uncommon (10\% for conduct disorder and $11 \%$ for being the victim of abuse), and even when these children were removed, violence rates remained high: $66 \%$ had a history of violence, $23 \%$ with severe violence, and $37 \%$ with internally driven violence; $37 \%$ had been violent to themselves, $43 \%$ had been violent to others, and $8 \%$ had been violent to animals.

Of the 35 children who had a history of internally driven violence, the age at which internally driven violence began was noted in 31 . Twenty (66\%) had their initial internally driven violent act concurrent with or after onset of psychosis, five (16\%) had the initial act in the year prior to onset of psychosis likely during the prodromal period, and six (19\%) had their initial internally driven violent act two or more years before onset of psychosis.

\section{Discussion}

Almost three-quarters of the psychotic children had been violent with one-third having been severely violent: approximately two-fifths of children had been violent towards themselves including several with suicide attempts; approximately half of case reviews included episodes of violence towards others. These rates showed very little reduction even when psychotic children with a history of being the victim of abuse or with comorbid conduct disorder were removed from the analysis. There is always a risk of an ascertainment bias where violent youth are more likely to be brought to clinical attention; however this rate of lifetime

Table 1. Demographics, violence rates, and victims of violence for 81 children with schizophrenia-spectrum disorders.

\begin{tabular}{lc} 
& N. (\%) \\
Gender & \\
Male & $24(30 \%)$ \\
Female & $57(70 \%)$ \\
Age & \\
4-7 years & $21(26 \%)$ \\
8-11 years & $42(52 \%)$ \\
12-15 years & $18(22 \%)$ \\
\hline Race/ethnicity & \\
Caucasian non-Hispanic & $58(72 \%)$ \\
Caucasian Hispanic & $12(15 \%)$ \\
African-American & $6(7 \%)$ \\
Mixed/other/unknown & $5(6 \%)$ \\
Diagnosis of: & \\
Schizophrenia & $53(65 \%)$ \\
Schizoaffective & $27(33 \%)$ \\
Psychosis NOS & $1(1 \%)$ \\
\hline Comorbidity & \\
Conduct disorder & $8(10 \%)$ \\
Victim of abuse & $9(11 \%)$ \\
History of: & \\
Any violence & $58(72 \%)$ \\
Severe violence & $25(31 \%)$ \\
Internally-driven violence & $35(43 \%)$ \\
\hline Victim & $33(41 \%)$ \\
Self & $41(51 \%)$ \\
Others & $12(15 \%)$ \\
Animals & \\
\hline
\end{tabular}


violence is similar to that found among mostly untreated psychotic young adults in a Swedish birth cohort. ${ }^{18}$ A notable percentage of the violence among the Swedish adults occurred prior to 18 years of age which may explain why these rates are higher than those found with methodologies that focus on more recent violence. ${ }^{19,20}$ In older adolescent samples, psychotic males are more likely to have a violence history than psychotic females. In this study of younger children, psychotic females were more likely to have been violent towards animals; there was no effect of gender on any other measure of violence in this study. Male/female differences may not develop until mid-adolescence.

There is some disagreement in the literature as to whether a portion of the violence risk ascribed to psychosis should instead be attributed to co-morbid substance use disorders. It is important to note that no child in this study had a substance use disorder at any time, including alcohol and nicotine; lifetime exposure for all the subjects in this study was low to non-existent. Thus, violence in this child population is not due to substance misuse.

Only one child met criteria for posttraumat-

Table 2. Examples of internally driven severe violence.

A 5 year-old male who repeatedly inserted items in his own rectum, stabbed the family dog and killed the family pet hamster with no evidence of remorse.

A 5 year-old male who, without provocation, grabbed a rock and severely beat up a female peer.

A 5 year-old male who tried to cut his own hair and lips off and repeatedly attacked his sister to the point he broke her arm.

A 6 year-old female who twisted the family dog's leg out of its socket.

A 6-year old male who tried to gouge his own eyes out.

A 6 year-old female who frequently shoves sticks down pets throats and who attacked her sister with a knife.

A 6 year-old male who, beginning at 3 years of age threatened peers with knives and repeatedly put his finger up his anus.

An 8 year-old female who placed thumbtacks point side up in the shag carpeting so the preschool-age children in the house would step on the thumbtacks. The same child snuck into her sister's room at night and shaved off her sister's eyebrows.

An 8-year old male who drunk poison to kill something he believed was growing in his back.

An 8-year male who, responding to auditory hallucinations, chased his sister with an intent to kill.

An 8 year-old female who tried to stab herself in the eye.

An 8-year old male who stabbed his sister in the neck.

A 9 year-old male who frequently tried to choke peers because it is fun.

A 9-year old female who attempted to rip out her brother's trachea.

A 9 year-old male who, beginning at 5 years of age has, in response to command hallucinations, repeatedly threatened peers with knives and assaulted adults.

A 10-year old male who repeatedly responded to command hallucinations to torture cats.

A 10-year old male who repeatedly attempted to strangle himself.

A 10-year-old male who has, in response to auditory hallucinations, repeatedly assaulted his mother and threatened her with a knife.

An 11 year-old male who put his hand through a glass door to determine if his hand or the door was stronger.

A 12 year-old male who inserted a tampon anally, would pull the wings off of insects and them set them afire, who repeatedly punched the family dog in the head, and who would rub himself with an eraser to get spots of his body.

A 12 year-old male who set fires in his closet and without provocation, threatened a neighbor with a knife.

A 12-year-old male who tortured and then killed the family rabbit, then burned it.

A 13 year-old male who broke into his neighbor's home with a plan to kill the neighbor boy with whom there was little previous contact. He was unable to provide any rationale except that he knew that the neighbor boy needed to die.

A 13-year old male who, although unprovoked, repeatedly attacked his classmates because he believed they were conspiring to harass him.

A 13-year old male who took a grenade to school and threatened to blow up the school.

Table 3. Impact of demographics and comorbidity on violence rates and victim identification.

\begin{tabular}{|c|c|c|c|c|c|c|c|c|c|c|c|c|c|c|c|}
\hline & $\begin{array}{c}\text { Any } \\
\text { violenc }\end{array}$ & & $\begin{array}{l}\text { Seve } \\
\text { viole }\end{array}$ & & & & $\begin{array}{l}\text { ly driven } \\
\text { ce }\end{array}$ & & & $s$ & & & s & $\begin{array}{l}\text { Violenc } \\
\text { to anim }\end{array}$ & als \\
\hline & N.H. P.H. & P* & N.H. P.H & P* & N.H. & DU & P* & N.H. & & P* & N.H. & & P* & N.H. P.H. & P* \\
\hline $\begin{array}{l}\text { Gender } \\
\text { Female } \\
\text { Male }\end{array}$ & $\begin{array}{ll}29 \% & 71 \% \\
28 \% & 72 \%\end{array}$ & 1.000 & $\begin{array}{ll}79 \% & 21 \% \\
65 \% & 35 \%\end{array}$ & 0.293 & $\begin{array}{l}8 \% \\
6 \%\end{array}$ & $\begin{array}{l}42 \% \\
44 \%\end{array}$ & 1.000 & $\begin{array}{l}50 \% \\
63 \%\end{array}$ & & & $\begin{array}{l}54 \% \\
47 \%\end{array}$ & & 0.632 & $\begin{array}{l}71 \% \\
91 \% \\
9 \%\end{array}$ & 0.035 \\
\hline $\begin{array}{l}\text { Age grouping } \\
\text { 4-7 years } \\
\text { 8-11 years } \\
12-15 \text { years }\end{array}$ & $\begin{array}{ll}24 \% & 76 \% \\
30 \% & 70 \% \\
28 \% & 72 \% \\
\end{array}$ & $\begin{array}{c}\chi^{2}(2) \\
=0.295 \\
P=0.863\end{array}$ & $\begin{array}{ll}59 \% & 41 \% \\
74 \% & 21 \% \\
67 \% & 33 \% \\
\end{array}$ & $\begin{array}{c}\chi^{2}(2) \\
=1.391 \\
\mathrm{P}=0.499\end{array}$ & $\begin{array}{l}47 \% \\
59 \% \\
61 \%\end{array}$ & $\begin{array}{l}53 \% \\
41 \% \\
39 \% \\
\end{array}$ & $\begin{array}{c}\chi^{2}(2) \\
=0.861 \\
P=0.650\end{array}$ & $\begin{array}{l}59 \% \\
59 \% \\
61 \% \\
\end{array}$ & & $\begin{array}{l}\chi^{2}(2) \\
=0.033\end{array}$ & $\begin{array}{l}29 \% \\
52 \% \\
61 \% \\
\end{array}$ & $\begin{array}{l}71 \% \\
48 \% \\
39 \% \\
\end{array}$ & $\begin{array}{l}\chi^{2}(2) \\
=3.846 \\
P=0.146\end{array}$ & $\begin{array}{ll}77 \% & 25 \% \\
87 \% & 13 \% \\
89 \% & 11 \% \\
\end{array}$ & $\begin{array}{l}\chi^{2}(2) \\
=1.333 \\
P=0.513\end{array}$ \\
\hline $\begin{array}{l}\text { Child abuse/negle } \\
\text { History } \\
\text { No history }\end{array}$ & $\begin{array}{cc}0 \% & 100 \% \\
32 \% & 68 \%\end{array}$ & 0.098 & $\begin{array}{ll}50 \% & 50 \% \\
71 \% & 29 \%\end{array}$ & 0.244 & $\begin{array}{l}50 \% \\
58 \%\end{array}$ & $\begin{array}{l}50 \% \\
42 \%\end{array}$ & 0.721 & $\begin{array}{l}13 \% \\
65 \%\end{array}$ & $\begin{array}{l}87 \% \\
37 \%\end{array}$ & 0.001 & $\begin{array}{l}25 \% \\
52 \%\end{array}$ & $\begin{array}{l}750 \\
480\end{array}$ & 0.264 & $\begin{array}{ll}63 \% & 37 \% \\
88 \% & 12 \%\end{array}$ & 0.092 \\
\hline $\begin{array}{l}\text { Conduct disorder } \\
\text { History } \\
\text { No history }\end{array}$ & $\begin{array}{ll}11 \% & 89 \% \\
31 \% & 69 \%\end{array}$ & 0.434 & $\begin{array}{ll}22 \% & 78 \% \\
75 \% & 25 \% \\
\end{array}$ & 0.003 & $\begin{array}{l}11 \% \\
63 \%\end{array}$ & $\begin{array}{l}89 \% \\
37 \%\end{array}$ & 0.004 & $\begin{array}{l}67 \% \\
58 \% \\
\end{array}$ & $\begin{array}{l}33 \% \\
42 \% \\
\end{array}$ & 0.731 & $\begin{array}{l}22 \% \\
58 \%\end{array}$ & $\begin{array}{l}78 \% \\
47 \% \\
\end{array}$ & 0.155 & $\begin{array}{ll}44 \% & 56 \% \\
90 \% & 10 \% \\
\end{array}$ & 0.003 \\
\hline
\end{tabular}

N.H. Negative history; P.H. positive history. *Probabilities are based on Fisher's Exact Test unless otherwise specified. P values less than 0.05 are in italics. 
ic stress disorder, although a history of trauma including exposure to abusive situations was present in approximately $11 \%$ of cases. All cases with a history of abuse also had a history of violence, and there was a non-significant trend for a history of being the victim of child abuse to be associated with an increased rate of violence. That trend was primarily explained by increased rates of violence towards self; there were no significant effects of a child abuse history on rates of severe violence, internally-driven violence, nor violence towards others. The percentage of psychotic subjects who had a history of violence remained high (above two-thirds) even when those with a history of child abuse were removed. When combined with the relatively low percentage of children in this study with abuse history, this suggests that child abuse is not a major cause of violence in children with schizophrenia.

Comorbid conduct disorder was identified in $8(10 \%)$ of the children and, consistent with what has been found in studies of adults with schizophrenia, ${ }^{21,22}$ this study identified comorbid conduct disorder as associated with increased prevalence of severe violence, internally-driven violence, and violence towards animals. However, because conduct disorder was relatively infrequent, when children with conduct disorder were removed, the violence prevalence rates remained high; the percentage who had committed violence towards others only dropped from $51 \%$ to $47 \%$ and the percentage who had committed severe violence only dropped from $31 \%$ to $25 \%$. Thus, comorbid conduct disorder was only a minor contributor to the overall violence level.

In addition to the rate of violent behavior, the type of violence seen may provide some instruction. Frustration intolerance, mood congruent self-harm behavior, and impulsive response to conflicts with others were present, but over $2 / 3$ of the children with violence exhibited internally driven violence, that is violence that occurred in the absence of any externally identifiable precursor. Notably, all cases of severe violence appeared to be violence that occurred independent of any externally identifiable goal or event (internally driven violence). Several authors have suggested that command hallucinations and a higher perception of threat (paranoid delusions) are a significant cause of more severe violent behavior in psychotic adults. ${ }^{23,24} \mathrm{~A}$ similar relationship, in this child sample, between positive psychotic symptoms and severe violence is suggested by the finding that over $80 \%$ of the severe violence episodes in this study occurred either after recognition of positive psychotic symptoms or in the year prior (likely during a prodromal period).

\section{Limitations}

A limitation of this chart review is the lack of an appropriate comparison group. Comparison to published rates of violence in other populations is also problematic. There are very few studies of violence in children this young and most focus on predictors of risk (e.g. carrying a knife or a gun) rather than on the actual act of violence. If the definition of violence is restricted to actual acts (versus thoughts or threats), this rate is higher than that reported for a sample of 9-12 year-olds being seen in central European pediatric practices; however, given the strong cultural impact on violence rates, ${ }^{25}$ this comparison is difficult to interpret. Thus, while the rates of a history of violence in this group of children with schizophrenia are high, it is unclear how they compare to other groups within this age range.

This report is a case series with cases identified through a tertiary referral program. While the referral process focused on clinician identification of subjects with possible positive symptoms, an ascertainment bias towards children with violence cannot be ruled out. Conversely, the information gathering process focused on clarifying diagnosis and a history of violence behavior may have been underemphasized and under-reported. Given these limitations, the rates of violent behavior should be considered an estimate.

\section{Clinical implications}

While some children had frequent violent behavior, for many others the violent acts and in particular the internally driven violent acts were rare or even isolated events. Despite their infrequency, they were often severe: suddenly attacking a peer with a rock, stabbing oneself in the hand with a knife, or breaking into a neighbor's home with intent to murder. In all cases where severe violence occurred, the violence appeared to be internally driven, often unrelated to external events. The combination of low frequency and lack of externally identifiable events makes this type of violence difficult to predict, and screening tools may be of low value. The apparent increased risk of violence during the early stage of the schizophrenic illnesses raises legal questions. ${ }^{26}$ However, the majority of severe violent acts occurred around the time of psychosis onset, prior to diagnosis and assessment. Thus, lowering the threshold for hospitalizing psychotic youth after they enter the mental health system is unlikely to have much impact on violence rates. Instead, generic safety issues like ensuring non-access to guns and knives or providing adequate adult supervision may be more effective prevention efforts than lowering the threshold for hospitalization.

Media attention to the rare event when a psychotic individual attempts or succeeds in a publically violent act as been shown to increase the stigma associated with a psychotic diagnosis. 27,28 It is unknown whether an increased focus on generic safety-oriented prevention strategies might also increase stigma or, if the prevention strategy is successful, might decrease the number of publicizable violent acts and thus decrease stigma.

For these children, the majority of violent episodes occurred prior to diagnosis and in the absence of antipsychotic treatment. There is strong evidence in older adolescents and adults that initial diagnosis and initiation of antipsychotic treatment dramatically reduces violence risk. ${ }^{29-31}$ For these younger children, the average length of psychotic symptoms prior to diagnosis and treatment initiation exceeded two years, 32 so there is a window for improvement. Earlier entry into the mental health system for diagnosis and rapid onset of treatment is likely to be the most effective method of reducing psychosis-related violence.

\section{Conclusions}

Violence, whether directed towards self or others, can causes significant morbidity including altered interaction between the child and his/her parents, withdrawal of peers, and potential agency involvement. The frequency, severity, and unpredictability of violence demonstrated by these psychotic children suggests a need for greater attention to addressing violence risk in children identified with psychosis. The attention should occur in both the clinical and research context.

\section{References}

1. Angermeyer MC. Schizophrenia and violence. Acta Psychiatr Scand 2000;102 Suppl 47:63-7.

2. Taylor PM. Psychosis and violence: Stories, fears, and reality. Can J Psychiatry 2008; 53:647-59.

3. Walsh E, Buchanan A, Fahy T. Violence and schizophrenia: examining the evidence. Br J Psychiatry 2002;180:490-5.

4. Fazel S, Gulati G, Linsell L, et al. Schizophrenia and violence: systematic review and meta-analysis. PLoS Medicine 2009;6:e1000120.

5. Arseneault L, Moffitt TE, Caspi A, et al. Mental disorders and violence in a total birth cohort. Arch Gen Psychiatry 2000;57:979-86.

6. Eronen M, Tiihonen J, Hakola P. Schizophrenia and homicidal behavior. Schizophr Bull 1996;22:83-9.

7. Heide KM, Boots DP. A comparative analy- 
sis of media reports of U.S. parricide cases with officially reported national crime data and the psychiatric and psychological literature. Int J Offender Ther Comp Criminol 2007;51:646-75.

8. Connor DF. Proactive and reactive aggression in referred children and adolescents. Am J Orthopsychiatry 2004;74:129-36.

9. Khalid FN, Ford R, Maughan B. Aggressive behaviour and psychosis in a clinically referred child and adolescent sample. Soc Psychiatry Psychiatr Epidemiol. [In press]

10. American Psychiatric Association. Diagnostic and statistical manual of mental disorders (4th edition). Washington DC: American Psychiatric Association Press; 1994.

11. Kaufman J, Birmaher B, Brent D, et al. Schedule for affective disorders and schizophrenia for school-age childrenPresent and lifetime version (K-SADS-PL): initial reliability and validity data. J Am Acad Child Adolesc Psychiatry 1997;36: 980-8.

12. Ross RG, Schaeffer J, Compagnon N, et al. Creating School-age versions of semistructured interviews for the prodrome to schizophrenia: lessons from case reviews. Schizophr Bull 2003;29:729-36.

13. Beresford C, Hepburn S, Ross RG. Schizophrenia in preschool children: 2 case reports with longitudinal follow-up for 5.92 and 8.6 years. Clinic Child Psychol Psychiatry 2005;10:429-39.

14. Phillips LJ, Yung AR, McGorry PD. Identification of young people at risk of psychosis: validation of personal assessment and crisis evaluation clinic intake criteria. Aust N Z J Psychiatry 2000;34 Suppl:S164-9.

15. Erkiran M, Õzünalan H, Evren C, et al. Substance abuse amplifies the risk for violence in schizophrenia spectrum disorder.
Addictive Behav 2006;31:1797-805.

16. Arseneault L, Moffitt TE, Caspi A, Taylor A. The targets of violence committed by young offenders with alcohol dependence, marijuana dependence and schizophreniaspectrum disorders: findings from a birth cohort. Criminal Behav Ment Health 2002;12:155-68.

17. Felthous AR. Schizophrenia and impulsive aggression: a heuristic inquiry with forensic and clinical applications. Behav Sci Law 2008;26:735-58.

18. Hodgins S. Mental disorder, intellectual deficiency, and crime. Evidence from a birth cohort. Arch Gen Psychiatry 1992;49:476-83.

19. Tiihonen J, Isohanni M, Rasanen $P$, et al. Specific major mental disorders and criminality: A 26-year prospective study of the 1966 Northern Finland Birth Cohort. Am J Psychiatry 1997;154:840-5.

20. Stueve A, Link BG. Violence and psychiatric disorders: results from an epidemiological study of young adults in Israel. Psychiatr Q 1997;68:327-42.

21. Hodgins S, Cree A, Alderton J, Mak T. From conduct disorder to severe mental illness: associations with aggressive behaviour, crime and victimization. Psychol Med 2008;38:975-87.

22. Hodgins S, Tiihonen J, Ross D. The consequences of conduct disorder for males who develop schizophrenia: associations with criminality, aggressive behavior, substance use, and psychiatric services. Schizo Res 2005;78:323-35.

23. Swanson JW, Swartz MS, Van Dorn RA, et al. A national study of violent behavior in persons with schizophrenia. Arch Gen Psychiatry 2006;63:490-9.

24. Stompe T, Ortwein-Swoboda G, Schanda H. Schizophrenia, delusional symptoms, and violence: the threat/control-override con- cept reexamined. Schizophr Bull 2004;30: 31-44.

25. Large M, Smith G, Nielssen 0 . The relationship between the rate of homicide by those with schizophrenia and the overall homicide rate: a systematic review and meta-analysis. Schizo Res 2009;112:123-9.

26. Nielssen 0, Large M, Ryan C, Hayes R. Legal implications of the incresed risk of homicide and serious violence in the first episode of psychotic illness. Criminal Law J 2007;31:287-94.

27. Angermeyer MC, Matschinger H. The effect of violent attacks by schizophrenic persons on the attitude of the public towards the mentally ill. Social Science \&amp; Medicine 1996;43:1721-8.

28. Angermeyer MC, Schulze B. Reinforcing stereotypes: how the focus on forensic cases in news reporting may influence public attitudes towards the mentally ill. Int J Law Psychiatry 2001;24:469-86.

29. Krakowski MI, Czobor P, Nolan KA. Atypical antipsychotics, neurocognitive deficits, and aggression in schizophrenia patients. J Clin Psychopharmacol 2008;28:485-93.

30. Large M. Evidence for a relationship between the duration of untreated psychosis and the proportion of psychotic homicides prior to treatment. Soc Psychiatry Psychiatr Epidemiol 2008;43: 37-44.

31. Nielssen 0, Large M. Rates of homicide during the first episode of psychosis and after treatment: a systematic review and meta-analysis. Schizophr Bull 2010;36: 702-12.

32. Schaeffer JL, Ross RG. Childhood-onset schizophrenia: premorbid and prodromal diagnostic and treatment histories. 2002;41:538-45. 